
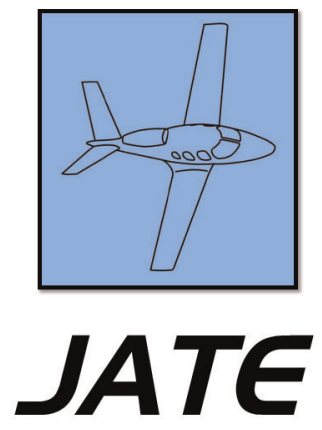

Journal of Aviation Technology and Engineering 7:2 (2018) 15-31

\title{
Efficiency Driver in Nigerian Airports: A Bootstrap DEA-Censored Quantile Regression Approach
}

\author{
Obioma Reuben Nwaogbe \\ Department of Transport Management Technology, Federal University of Technology, Minna, Nigeria \\ Peter Wanke \\ COPPEAD Graduate Business School, Federal University of Rio de Janeiro \\ Innocent Chukwuka Ogwude \\ Department of Transport Management, Federal University of Technology Owerri State Nigeria \\ Carlos Pestana Barros \\ Instituto Superior de Economia e Gestão, University of Lisbon \\ Abul Kalam Azad \\ Department of Applied Statistics, Faculty of Economics and Administration, University of Malaya
}

\begin{abstract}
This paper reports on the use of a novel two-stage approach for assessing the efficiency of 30 major Nigerian airports from 2003 to 2013 based on bootstrapped data envelopment analysis (DEA) and censored quantile regression. In the first stage, bootstrapped efficiency estimates are computed. They enable bias correction and testing for significant differences in efficiency levels among airports. Subsequently, bootstrapped DEA results are combined with censored quantile regression to assess the impact of contextual variables-related to the airports' ownership, location, and network connectivity—on different efficiency percentiles. The results reveal that the intensity of significant impacts regarding airports' contextual variables may vary between high-/low-efficiency airports. Policy implications are derived accordingly.
\end{abstract}

Keywords: airports, DEA, bootstrap, Nigeria, censored quantile regression

All correspondence concerning this article should be directed to Obioma Reuben Nwaogbe at obioma.nwaogbe@ @utminna.edu.ng. 


\section{Introduction}

Research on airport efficiency has adopted several methods, such as the factor productivity approach; stochastic frontier analysis (SFA) models (Barros, 2009; Diana, 2010); the Turnquist total factor productivity index; and data envelopment analysis (DEA) models (Adler \& Berechman, 2001; Barros \& Dieke, 2008; Gillen \& Lall, 1997; Titko, Stankevičienè, \& Lāce, 2014). Previous studies analyzed airports from different countries and regions worldwide. However, the most commonly analyzed are usually European and North American airports, while African airports are rarely investigated (Barros, 2014; Wanke, Barros, \& Nwaogbe Obioma, 2016). This paper adds to the current body of knowledge by analyzing the efficiency of Nigerian airports using a novel two-stage model built upon bootstrapped DEA and censored quantile regression $(\mathrm{CQR})$.

The motivations for the present research are twofold. First, despite intense research on airport efficiency, few international peer-reviewed papers tackle Nigerian airports (Wanke et al., 2016). Whilst some data on remote Nigerian airports have been published (Bråthen, 2016), the focus on African airports, in a broader sense, remains a research gap with few papers published on the issue (Barros, 2014), which would bring an important contribution to the overall analysis of airport efficiency. A major reason for this under-researched context is that the Air Transport Research Society Airport Benchmark Annual Report does not present data on African airports. The second motivation for the present study is the highly significant role of the air transportation industry in Nigeria, due to the fact that it does not have any other competitor in terms of speed and safety for passengers and cargo shipment around the country.

Besides, this paper is innovative in the literature of airport efficiency at the country level by adopting a two-stage bootstrapped DEA-CQR approach. Basically, the relative performance of Nigerian airports is evaluated with respect to distinct efficiency percentiles, assessing, for instance, how different contextual variables related to ownership, location, and network coverage differently impact highand low-efficiency airports. In this research, this two-stage approach is carried out for the first time on airport efficiency. This being the case, policy implications are derived for different percentiles of efficiency levels. Therefore, this paper contributes to the literature on airport efficiency, not only by analyzing the airports of the most populous African country, but also by using bootstrapped DEA-CQR for the first time in this context.

The remainder of this paper is organized as follows. The next section presents the contextual setting of airports in Nigeria. This is followed by a literature review, and then a section containing the data and the methodology. The empirical results are then presented and discussed in terms of policy implications, while the conclusions are outlined in the final section.

\section{Contextual Setting}

Nigeria is a West African country and a former British colony that attained self-government in 1960. In 1967, the country adopted a subdivision into a twelve-state structure. In 1976, the number of regions increased to nineteen states; twenty-one in 1987; thirty in 1991; and, since 1996, it has been comprised of thirty-six states. During colonial times there were only three airports: Lagos, Kano, and Maiduguri. Nigeria currently has twenty-one airports, five of which are international airports. The international airports are the Murtala Muhammed Airport in Lagos, where the seat of government was established until 1991; the Aminu Kano Airport in Kano, a commercial hub city; the Kaduna, at Port Harcourt; and the Abuja airports. The last two cities have a high volume of commercial activities, and Abuja is currently the federal capital.

Nigerian airport facilities are old or poorly maintained, with an aging workforce. There is a poor level of operational efficiency and safety (Wanke et al., 2016). In 2006, the government promulgated the Civil Aviation Act in order to overcome these organizational problems. The airports are managed by the Federal Airports Authority of Nigeria (FAAN), an entity established in 1995. In 1999, another restructuring took place in order to conform to the International Civil Aviation Organization, enabling then the separation of regulatory bodies from service providers. Table 1 presents some characteristics of the physical production of Nigerian airports as of 2013. Furthermore, the airports are divided into domestic and international airports, as a result of a decision of the Federal Government of Nigeria. Therefore, researchers have to adopt the way the airports were set up by the government.

\section{Literature Review}

There are a growing number of studies focusing on airport efficiency (Diana, 2010). Specifically, there are two dominant schools of methodology for assessing efficiency: the mathematical programming approach, which is well known by the DEA method and its variations; and the SFA approach, which has its roots in econometric theory (Bogetoft \& Otto, 2010). In detail, while the slack analysis of DEA provides insight on resources to improve efficiency discrimination, the SFA method focuses on the economic justification of a given production function. Besides, SFA implies some advantages over DEA as well as disadvantages because of its parametric characteristics, where some distributional assumptions are made regarding the error and the inefficiency terms. DEA, on the other hand, has some key advantages over SFA due to its nonparametricdistribution free-characteristics and due to the capability 
Table 1

Characteristics of Nigerian airports analyzed in 2013.

\begin{tabular}{|c|c|c|c|c|c|}
\hline No. Obs & Airports & No. of Passengers (000) & No. of Aircraft (000) & Terminal Capacity (Pax) & No. of Employees \\
\hline 1 & ABJ DOM & $3,015,803$ & 48,561 & 252 & 808 \\
\hline 2 & ABJ INT'L & 854,129 & 8,592 & 320 & 934 \\
\hline 3 & AKURE & 8,789 & 1,254 & 40 & 72 \\
\hline 4 & BENIN & 217,254 & 4,504 & 250 & 95 \\
\hline 5 & CAL DOM & 172,810 & 3,126 & 108 & 153 \\
\hline 6 & CAL INT'L & 234 & 13 & 100 & 116 \\
\hline 7 & ENUGU & 225,915 & 3,631 & 300 & 149 \\
\hline 8 & IBADAN & 56,959 & 2,915 & 250 & 87 \\
\hline 9 & ILO DOM & 52,938 & 2,479 & 202 & 72 \\
\hline 10 & ILO INT'L & 0 & 0 & 200 & 111 \\
\hline 11 & JOS & 47,910 & 1,202 & 250 & 121 \\
\hline 12 & KAD DOM & 144,583 & 3,471 & 285 & 107 \\
\hline 13 & KAD INT'L & 22,785 & 138 & 250 & 153 \\
\hline 14 & KAN DOM & 202,934 & 5,117 & 600 & 466 \\
\hline 15 & KAN INT'L & 127,824 & 1,803 & 640 & 532 \\
\hline 16 & MKD & 1,117 & 289 & 63 & 43 \\
\hline 17 & MAID DOM & 72,301 & 1,386 & 200 & 168 \\
\hline 18 & MAID INT'L & 11,935 & 80 & 50 & 130 \\
\hline 19 & MMA DOM & $3,454,250$ & 65,006 & 615 & 1252 \\
\hline 20 & MMA INT'L & $3,395,872$ & 31,543 & 3675 & 1390 \\
\hline 21 & PHC DOM & $1,113,183$ & 20,782 & 518 & 360 \\
\hline 22 & PHC INTL & 129,176 & 2,845 & 700 & 299 \\
\hline 23 & SOK DOM & 78,377 & 2,161 & 194 & 54 \\
\hline 24 & SOK INT & 32,088 & 103 & 250 & 78 \\
\hline 25 & YOLA DOM & 123,421 & 3,172 & 108 & 124 \\
\hline 26 & YOLA INT'L & 8,260 & 43 & 120 & 127 \\
\hline 27 & MINNA & 8,789 & 520 & 1000 & 101 \\
\hline 28 & KAT & 2,456 & 475 & 120 & 119 \\
\hline 29 & OWERRI & 279,609 & 4,560 & 800 & 131 \\
\hline \multirow[t]{4}{*}{30} & OSUBI & 246,560 & 8,256 & 65 & 20 \\
\hline & Mean & 463,041 & 7,601 & 418 & 279 \\
\hline & Median & 75,339 & 2,662 & 250 & 126 \\
\hline & Std Dev & 990,423 & 15,049 & 662 & 356 \\
\hline
\end{tabular}

Source: FAAN.

of simultaneously handling several outputs. Nevertheless, DEA falls short with respect to the necessary statistical properties for a robust examination of the inefficiency roots when using contextual variables. Bootstrapping, however, is one of the most attractive solutions to overcome this major DEA shortcoming, i.e., no statistical properties (Assaf, 2010). A summary of DEA-based airport efficiency studies is presented in Table 2 along with some of their major features: inputs and outputs used, number of decisionmaking units (DMUs) analyzed, country of study, data nature (cross-sectional or longitudinal), and the methodology.

The first study on airport efficiency using DEA was conducted by Schefczyk (1993). In a survey paper, Liu, $\mathrm{Lu}, \mathrm{Lu}$, and Lin (2013) reported that DEA papers on transportation-mainly related to airport efficiency-account for almost $8 \%$ of total DEA papers. An overview of major airport efficiency can be found in Yu (2010). More recently, a detailed literature review of 45 years of airport performance measurement is given in Bezerra and Gomes (2016). Broadly speaking, and in accordance with those authors, these studies are mainly focused on (1) examining airport efficiency to measure benchmarks for monitoring airport operations; (2) examining contextual variables for explaining airport performance; and (3) measuring capacity excess or shortfall in terms of input and output slacks (Wanke et al., 2016). Furthermore, Barros, Wanke, Nwaogbe, and Azad (2017) studied the efficiency in Nigerian airports using a stochastic frontier model by adopting the methodology presented in Alvarez et al. (2004) - the AAG model. The study findings show that under a modified version of the AAG model, inputs and outputs are separated in frontier and allowing contextual variables to control the impacts of managerial ability on efficiency. Also, the variation in efficiency scores is more sensitive to labor than to capital costs, and it also indicates a negative impact of regulation and hub operations on efficiency levels.

A closer look within each paper reveals that the most common inputs are employees, terminal area or capacity, runways, various kinds of assets, and costs; while the most frequent outputs encompass revenues, profits, movements (landings and take-offs), and passenger throughput. Therefore, in this research, as the inputs, we use the terminal capacity (in pax/year), the runway dimensions (in $\mathrm{m}^{2}$ ), the number of employees, the total assets (in current NGN), and the total 


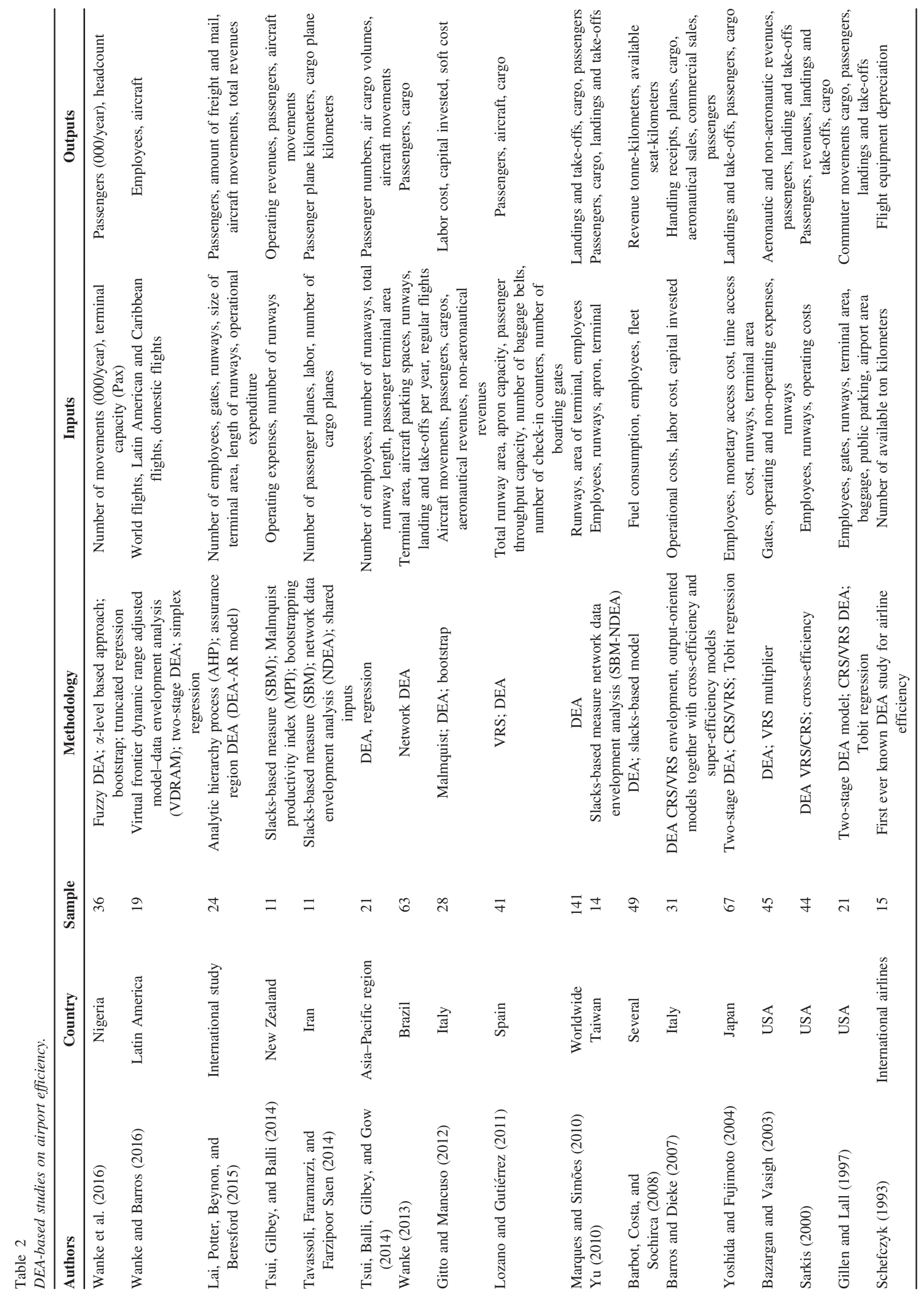


costs (in current NGN per year). The outputs used involve the passenger throughput per year and the number of aircraft movements per year. It is important to notice that so far no study has adopted simultaneously bootstrapped DEA and $\mathrm{CQR}$ in a two-stage approach. Furthermore, no research has performed such analysis focusing on the airport industry at the country level, an additional uniqueness of this paper.

\section{Methodology}

\section{The Data}

The data on 30 Nigerian airports were obtained from FAAN and encompass the period from 2003 to 2013. The inputs and the outputs selected were not only those commonly found in the literature review but also those dependent on data availability. The input variables included terminal capacity (in pax/year), the runway dimensions (in $\mathrm{m}^{2}$ ), the number of employees, the total assets (in current NGN), and the total costs (in current NGN per year). The output variables were the passenger throughput per year and the number of aircraft movements per year. The descriptive statistics are shown in Table 3.

An additional four contextual and business-related variables were collected to explain differences in the efficiency levels. These variables are also presented in Table 3 and are related to major elements of the airport cost structure-(1) labor cost (measured as the total wages/ number of employees ratio); (2) capacity cost (measured as the total assets/terminal capacity ratio); and (3) movement cost (measured as the total costs/total landings and takeoffs ratio) - and the airport regulation which is a dummy variable for the period that the regulation was adopted. Linear and squared trend components were also considered in the analysis.

This sample of 30 DMUs is comparable in size to similar DEA applications, as presented in Table 2-mean of 37 DMUs per study. According to Cooper et al. (2001), the number of DMUs is a relevant issue when using DEA as the cornerstone methodology. It should be at least three times higher than the number of inputs and outputs.

Correlation analyses indicate significant positive relationships between the inputs and the outputs, which are, therefore, isotonic and justified to be included in the model (Marques \& Simões, 2010). A correlogram for the matrix of inputs and outputs is presented in Figure 1. The Figure 1 correlation analysis for thirty Nigerian airports shows various significant relationships between the inputs and output correlation matrix. This correlation matrix will inform the government on various policy implications for the relationships that exist between the input and the output variables.

Contextual variables presented in Table 3 relate to the airport network connectivity, whether the airport is a hub (1) or is not a hub (0); whether the airport operates international flights (1) or does not operate international flights (0); to the airport location, whether the airport is located in large metropolitan areas (1, above 2.5 million inhabitants) or small metropolitan areas (0, below 2.5 million inhabitants); whether the airport is seashore located (1, up to $35 \mathrm{~km}$ from the seashore) or inland located ( 0 , beyond $35 \mathrm{~km}$ from the seashore); whether the airport ownership is private (1) or public (0). Linear and squared trend components were also considered.

There are several reports in the literature relating the positive and statistically significant impact on airport efficiency of such variables. Gillen and Lall (1997), Sarkis (2000), Bazarghan and Vasigh (2003), and Barros and Dieke (2008) found a positive impact of hub and spoke network models on airport efficiency. The basic idea is that the location of a hub at an airport greatly increases many airport output measures, including revenue and passenger flows.

The same occurs with international airports (Barros \& Dieke, 2008; Tsekeris, 2011), since in some ways they operate as a hub for the surrounding region, which may be touristic or metropolitan. Furthermore, and for similar reasons, location in populated and/or wealthy areas, close

Table 3

Summary statistics for the sample.

\begin{tabular}{|c|c|c|c|c|c|c|}
\hline \multicolumn{3}{|l|}{ Variables } & \multirow{2}{*}{$\frac{\text { Min. }}{40}$} & \multirow{2}{*}{$\frac{\text { Max. }}{3,675}$} & \multirow{2}{*}{$\begin{array}{c}\text { Mean } \\
418\end{array}$} & \multirow{2}{*}{$\frac{\text { SD }}{662}$} \\
\hline Inputs & Terminal capaci & x/year) & & & & \\
\hline & Runway dimens & $\left.\mathrm{n}^{2}\right)$ & 81,000 & $1,213,435$ & 190,540 & $200,792.8$ \\
\hline & Number of emp & & 20 & 1,390 & 279 & 356 \\
\hline & Total assets (cu & NGN) & $15,881,0721.3$ & $78,345,380,972$ & $8,934,796,863$ & $15,555,864,757$ \\
\hline & Total costs (cur & JGN per year) & 2283221.04 & $4,354,835,610$ & $548,697,247.8$ & $921,899,168.5$ \\
\hline \multirow[t]{2}{*}{ Outputs } & Passenger throu & (pax per year) & - & $3,454,250$ & 463,041 & 990,423 \\
\hline & Aircraft movem & per year) & - & 65,006 & 7,601 & 15,049 \\
\hline \multirow{8}{*}{$\begin{array}{l}\text { Contextual } \\
\text { variables }\end{array}$} & Trend & Linear & 1.00 & 11.00 & 6.00 & 3.17 \\
\hline & component & Squared & 1.00 & 121.00 & 46.00 & 39.02 \\
\hline & Ownership & Private & - & 1.00 & 0.03 & 0.18 \\
\hline & Location & Seashore & - & 1.00 & 0.23 & 0.42 \\
\hline & & Large metropolitan & & & & \\
\hline & & area & - & 1.00 & 0.63 & 0.48 \\
\hline & Network & Hub & - & 1.00 & 0.13 & 0.34 \\
\hline & connectivity & International flights & - & 1.00 & 0.33 & 0.47 \\
\hline
\end{tabular}




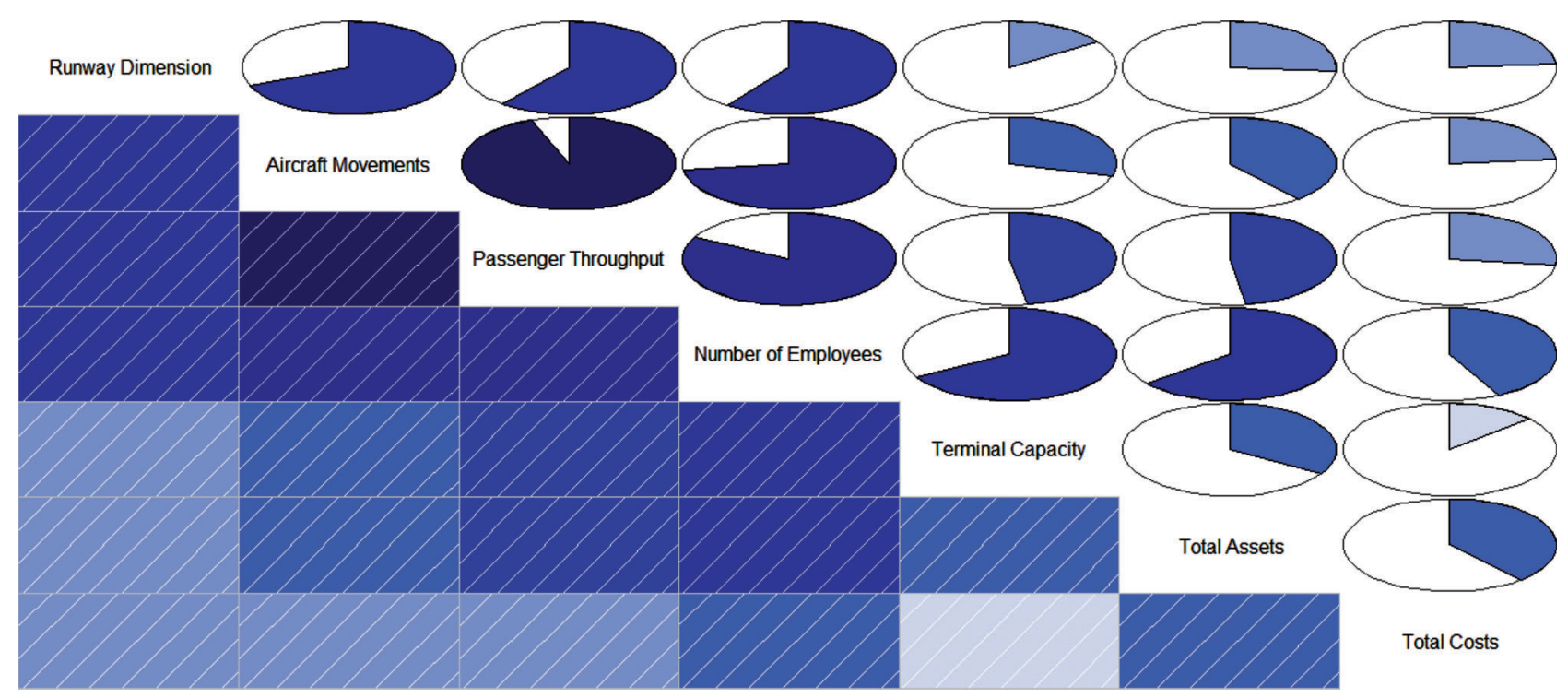

Figure 1. Graphic correlogram for the matrix of inputs and outputs.

to the seashore, may also affect airport efficiency (Martin \& Roman, 2001; Tsekeris, 2011) once these areas generate a natural demand for airport services (Barros \& Dieke, 2008).

An important underlying assumption considered by those authors is that these contextual variables are exogenous, that is, they affect efficiency levels without being affected by them. Here, hub, international, large metropolitan area, seashore, and private represent, therefore, decision variables based on FAAN's discretion rather than endogenous variables generated within the ambit of an efficiency model or a production process.

\section{Data Envelopment Analysis}

DEA is a nonparametric model first introduced by Charnes et al. (1978; Cooper et al., 2001; Wang et al., 2011). It is based on linear programming and is used to address the problem of calculating relative efficiency for a group of DMUs by using multiple measures of inputs and outputs. Given a set of DMUs, inputs, and outputs, DEA determines for each DMU a measure of efficiency obtained as a ratio of weighted outputs to weighted inputs.

Consider a set of $n$ observations on the DMUs: each observation, $D M U_{j}(j=1, \ldots, n)$, uses $m$ inputs $x_{i j}(i=1, \ldots, m)$ to produce $s$ outputs $y_{r j}(r=1, \ldots, s)$. DMU $U_{o}$ represents one of the $n$ DMUs under evaluation, and $x_{i o}$ and $y_{r o}$ are the $i^{\text {th }}$ input and $r^{\text {th }}$ output for $D M U_{o}$, respectively. Table 4 presents the envelopment model for the varying returns to scale (VRS) frontier type, where $\varepsilon$ is a non-Archimedian element and $s_{i}^{-}$and $s_{r}^{+}$account, respectively, for the input and output slack variables (Bazarghan and Vasigh, 2003; Zhu, 2003).

Despite the fact that the orientation of the model is not a consensual aspect of the efficiency models in airports
Table 4

DEA output-oriented envelopment model.

\begin{tabular}{ll}
\hline Frontier Type & \multicolumn{1}{c}{ Envelopment Model } \\
\hline & $\max \phi-\varepsilon\left(\sum_{i-1}^{m} s_{i}^{-}+\sum_{r-1}^{s} s_{i}^{+}\right)$ \\
& s.t. \\
& $\sum_{j-1}^{n} \lambda_{j} x_{i j}+s_{i}^{-}=x_{i o}, \forall i$ \\
VRS, also known as & $\sum_{j-1}^{n} \lambda_{j} y_{r j}-s_{i}^{+}=\phi y_{r o}, \forall r$ \\
BCC (Banker & $\lambda_{j} \geq 0, \forall j$ \\
et al., 1984) & $\sum_{j-1}^{n} \lambda_{j}=1$
\end{tabular}

(Marques \& Simões, 2010) (refer to Table 2), an output maximization orientation is adopted here. Under these circumstances, decision-makers should attempt to maximize production outputs for a given level of inputs, supposedly fixed in the short term. Regardless, the output-increasing potential should be always interpreted with care, since in the absence of demand it may be meaningless (Odeck \& Alkadi, 2001).

\section{Bootstrapping}

Nonparametric efficiency estimators such as DEA typically rely on linear programming techniques for computation of estimates, and are often characterized as deterministic, as if to suggest that the methods lack any statistical underpinnings (Simar \& Wilson, 2004). Applied studies that have used these methods have typically presented point estimates of inefficiency, with no measure or even discussion of uncertainty surrounding these estimates (Cesaro et al., 2009). Indeed, many papers contain statements where 
efficiency is described as being computed or calculated as opposed to being estimated, and results are frequently referred to as efficiencies rather than efficiency estimates (Ray, 2010; Zarepisheh et al., 2010).

The choice of terminology in describing the nonparametric efficiency approaches and their results is perhaps understandable given, until very recently, the lack of a "tool box" with aids for diagnostics, inference, etc., such as the one available to researchers using parametric approaches (Simar \& Wilson, 2004). To solve these problems, bootstrap techniques have been introduced into DEA analysis (Cesaro et al., 2009). The bootstrap technique permits the sensitivity of efficiency scores relative to the sampling variation of the frontier to be analyzed, avoiding problems of asymptotic sampling distributions.

DEA results, in fact, may be affected by sampling variation in the sense that distances to the frontier are underestimated if the best performers in the population are not included in the sample. To account for this, Simar and Wilson $(1998,2000)$ originally proposed a bootstrapping method that relies on smoothing the empirical distribution, allowing the construction of confidence intervals for DEA efficiency scores. This technique consists of a simulation of a true sampling distribution by mimicking a data generating process, using the outputs from DEA. In this way, a new dataset is created and DEA is re-estimated using this dataset. Repeating the process many times allows the achievement of a good approximation of the true distribution of the sampling (Cesaro et al., 2009).

Generally speaking, statistical inference based on a nonparametric frontier approach may be useful to determine whether a productive unit is actually operating at its most productive scale size or not. When a productive unit is found to be operating in the region of increasing returns to scale, an implied judgment is that it is smaller than its optimal size (Ray, 2010). Similarly, a firm operating in the region of diminishing returns to scale is considered to be too large.

The method used in this research departs from that presented by Simar and Wilson (2004, which adapted the bootstrap methodology to the case of DEA efficiency estimators and uses a Gaussian kernel density function for random data generation. All the computations were carried out with R codes developed by the authors; 200 bootstrap replications were performed on model (1), following the discussion presented by Simar and Wilson (1998, 2004) and Curi et al. (2011) on deriving statistical properties for each airport vis-à-vis bias estimation, and central tendency correction.

\section{Censored Quantile Regression}

Traditional regression models cannot answer an important question: "do contextual variables influence efficiency levels differently for low-efficiency Nigerian airports and for those with high or average efficiency levels?" A more comprehensive picture of the effect of the contextual variables on the efficiency levels can be obtained via CQR. Quantile regression models the relation between a set of contextual variables and specific percentiles (or quantiles) of the response variable. It specifies changes in the quantiles of the efficiency. For example, a median regression (50th percentile) of efficiency on an airport's contextual variables specifies the changes in the median efficiency as a function of these predictors. In this sense, the effect of private ownership on median efficiency levels can be compared to its effect on other quantiles of efficiency in Nigerian airports. As a matter of fact, the quantile regression parameter estimates the change in a specified quantile of the response variable produced by a one unit change in the predictor variable. This allows comparison of how some percentiles of the efficiency levels may be more affected by certain airport characteristics or contextual variables than other percentiles. This is reflected in the change in the size of the regression coefficient.

According to Leng and Tong (2013), the quantile regression was introduced by Koenker and Bassett (1978) and has become an increasingly important tool in statistical analysis. They have actually introduced the general quantile regression estimation that became the most popular approach (Hong \& Chernozhukov, 2002). Contrary to the usual model for the conditional mean, it provides distributional information on the dependence of $T$ on $Z$. The $T$ th conditional quantile function of the dependent variable $T$ given covariates $Z, Q_{T}(T \mid Z)$, is defined as $Q_{T}(T \mid Z)=$ $\inf \left\{v: F_{0}(v \mid Z) \geqslant T\right\}$, where $F_{0}$ is the cumulative conditional distribution function of $T$ given $Z$. Correspondingly, a quantile regression model for $Q_{T}(T \mid Z)$ with $T \in(0,1)$ can be denoted as

$$
Q_{T}(T \mid Z)=\beta_{T}^{\prime} \mathrm{Z}
$$

When data are subject to censoring, statistical estimation and inference for quantile regression are more involved. Indeed, a naive procedure which completely ignores censoring may give highly biased estimates (Koenker and d'Orey, 1987). Equivariance to monotone transformations is an important property of quantile regression models (Powell, 1986).

Powell $(1984,1986)$ first studied CQR with fixed censoring. For random censoring, Ying et al. (1995) proposed a semiparametric median regression model. Despite the simplicity of their method, this procedure requires the unconditional independence of the survival time and censoring time. This assumption is often restrictive as conditional independence, given the covariates, is more natural (Kalbfleisch \& Prentice, 2002). In addition, the estimating equation approach proposed in Ying et al. (1995) involves solving non-monotone discrete equations, creating difficulty for optimization. As a consequence, inferential procedures such as the resampling approach in Jin et al. (2001), or the bootstrap method, can be computationally prohibitive. 

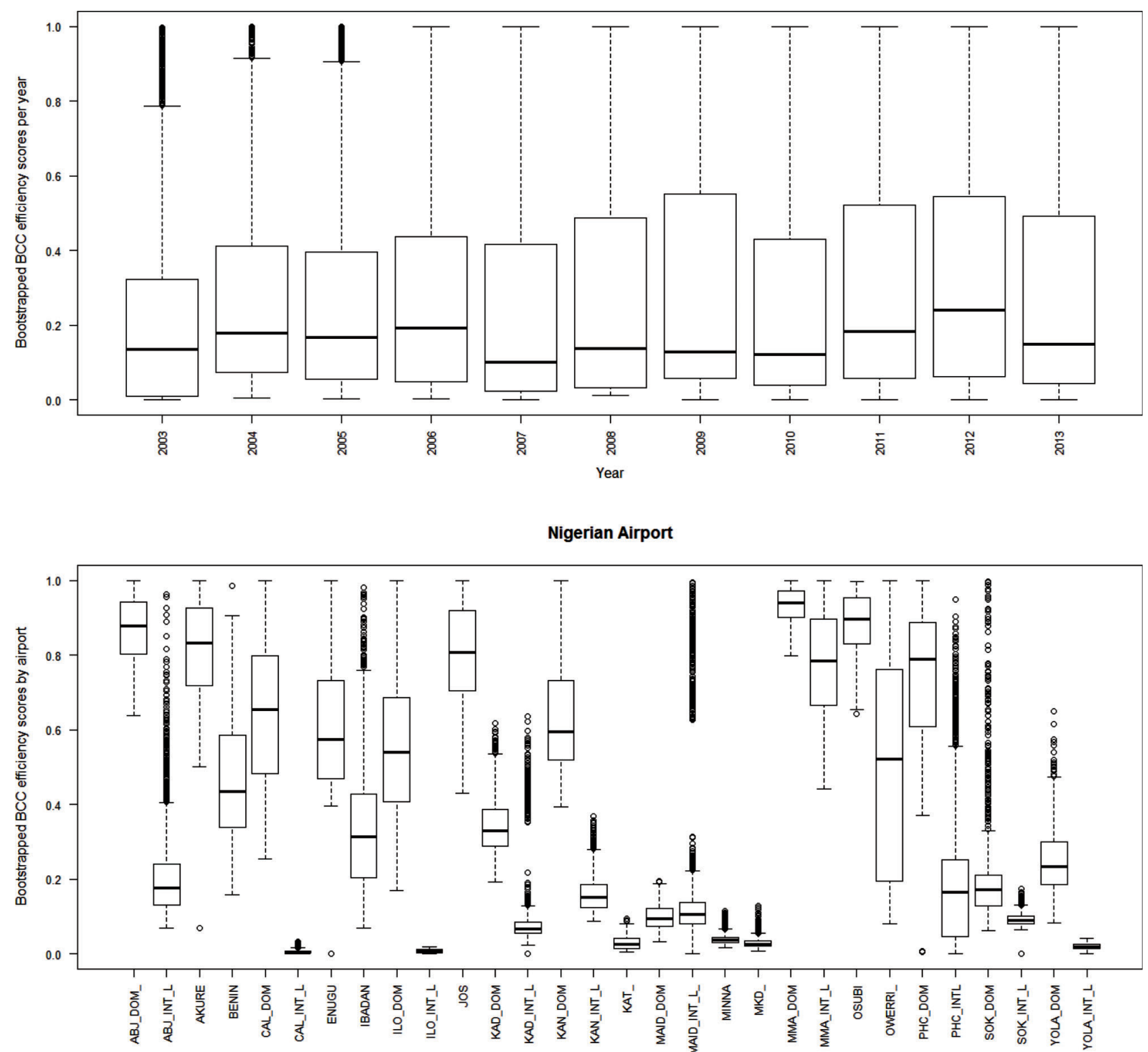

Figure 2. Efficiency levels grouped by year and by airports.

Hong and Chernozhukov(2002) argue that the CQR models allow covariates to shift location, scale, and the entire shape of the distribution and permit distribution-free specifications. As such, CQR models compare favorably to the normal Amemiya-Tobin, Cox, Buckley-James, and other approaches. According to the authors, in this model, the latent variable $Y_{i}^{*}$ is left censored by the observable, possibly random, censoring points $\mathrm{Ci}$, and we observe

$$
Y_{i}=Y_{i}^{*} \vee C_{i}, X_{i}, C_{i}, \sigma_{i}=1\left(Y_{i}=C_{i}\right)
$$

$Y_{i}^{*}$ is assumed to be conditionally independent of the censoring point $C_{i}$; that is, for all $y \in \mathrm{IR}$,

$$
P\left(Y^{*}<y \mid X_{i}, C_{i}\right)=P\left(Y^{*}<y \mid X_{i}\right) \text {, so that } Q_{Y^{*} \mid X_{i}, C_{i}}(T \mid Z)=\beta_{T}^{\prime} Z
$$

Conditioning on $C_{i}$, equation (5), and the equivariance transformation yield the following CQR model (Powell, 1986):

$$
Q_{Y_{i} \mid X_{i}, C_{i}(T \mid Z)}=\beta_{T}^{\prime} Z \vee C_{i}
$$

\section{Results and Discussion}

The efficiency levels calculated for 30 Nigerian airports from 2003 to 2013, using bootstrapped DEA and considering different grouping criteria, are given in Figures 2, 3, and 4. More precisely, in Figure 2 (top), bootstrapped DEA scores are grouped by year, and in Figure 2 (bottom) these scores are shown by airport. It is worth noting that, 


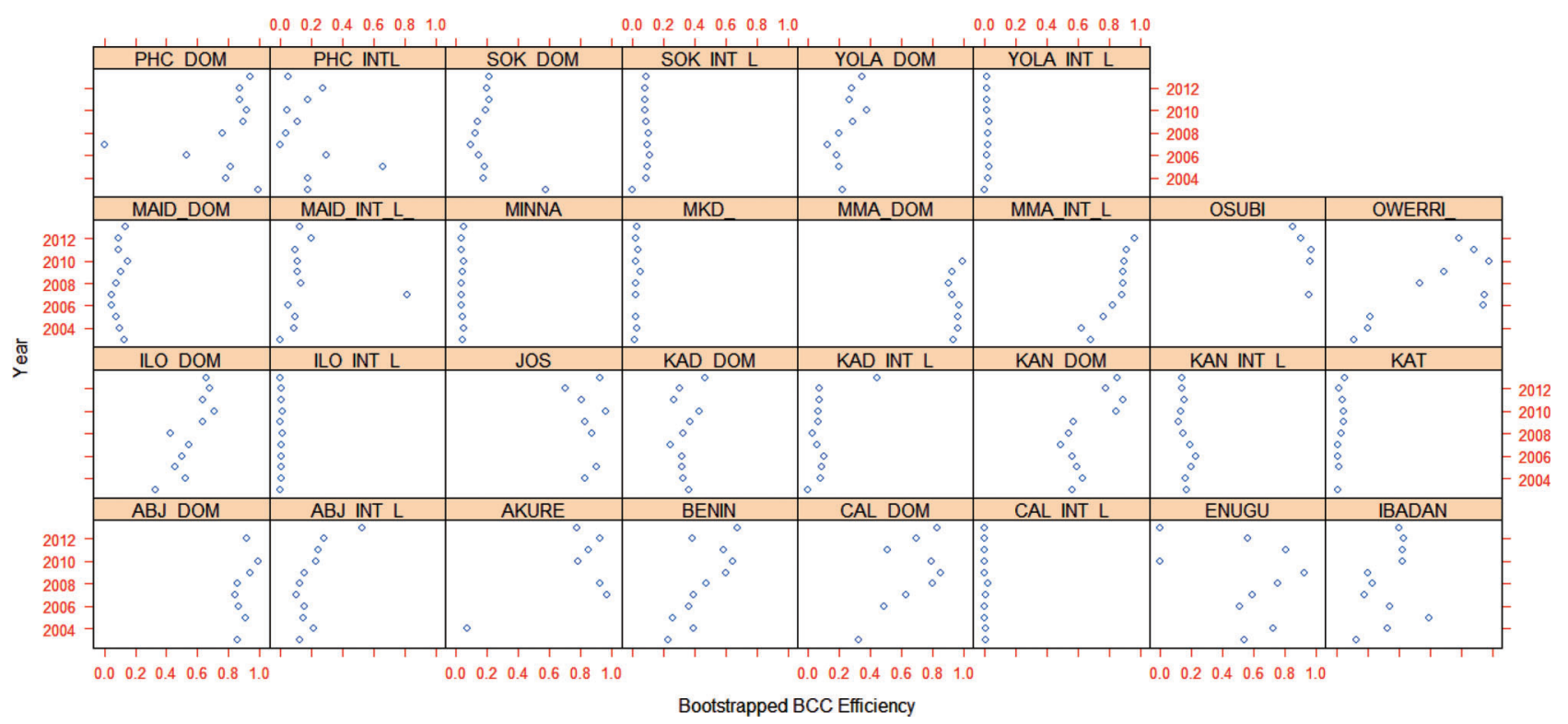

Figure 3. Efficiency levels grouped by airport over the course of time.
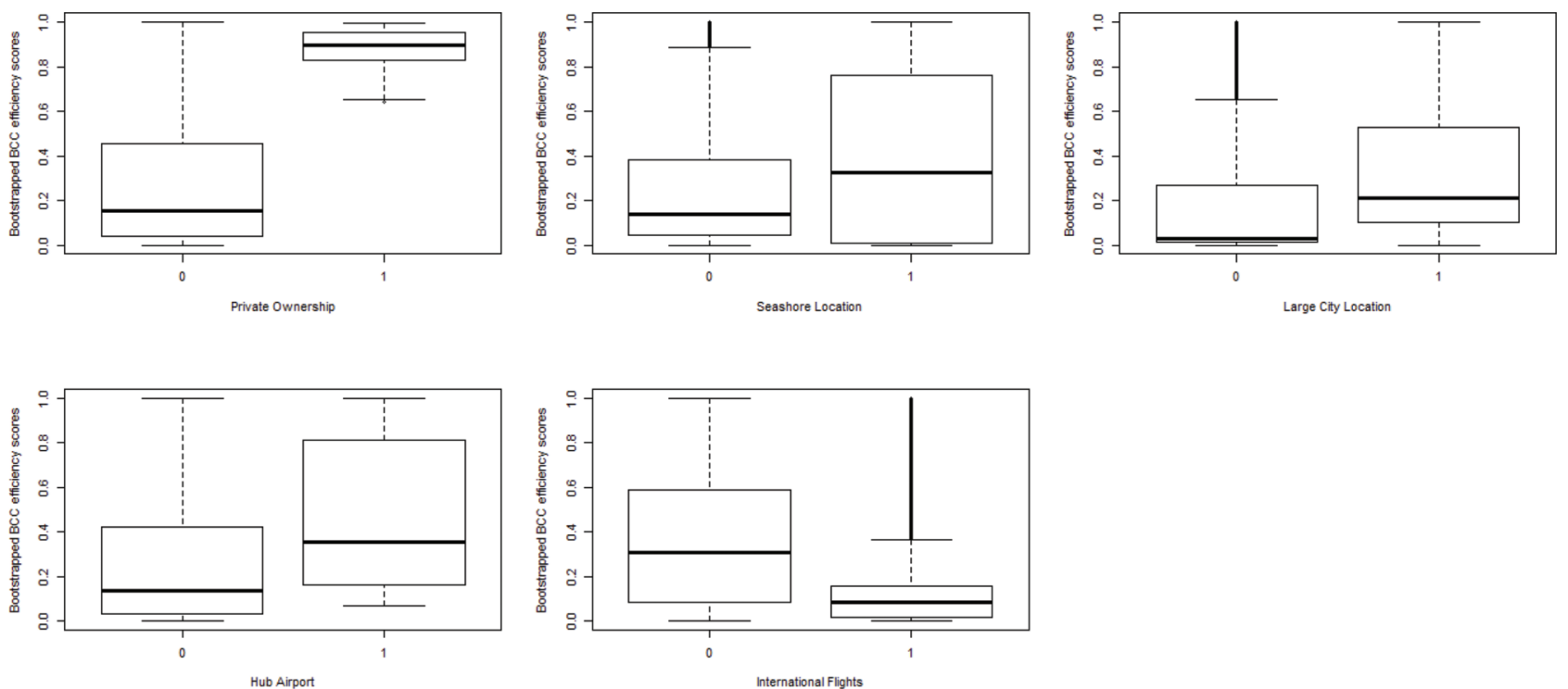

Figure 4. Bootstrapped DEA efficiency scores by contextual variables.

although median efficiency levels are quite stable over the analyzed period (Kruskal-Wallis test for median differences did not show significant results), substantial differences come to light when efficiency levels are grouped by airport.

A clear picture emerges when efficiency levels are grouped by airport and year (cf. Figure 3). Fluctuations in efficiency levels appear to be very high not only within some airports-apparently it is not possible to infer a growing trend for the majority of them-but also between them. This suggests the eventual impact of contextual variables that may be embedded within these grouping schemes. In fact, median efficiency levels are higher in private airports with hub operations, which are located close to the seashore, and serve large metropolitan areas. On the other hand, median efficiency levels appear to be lower in airports that operate international flights (cf.Figure 4).

Results for the CQR of the efficiency scores on these five contextual variables are presented for selected efficiency percentiles in Table 5 ( $\operatorname{tau}=0.20,0.40,0.60$, and 0.80). The full set of results for the percentile range from 0.05 to 0.95 in intervals of 0.05 is given in the Appendix and depicted in Figure 5. Significances and bootstrapped lower and upper confidence intervals can also be found in the Appendix. The standard errors and confidence limits for the CQR coefficient estimates were obtained with asymptotic and bootstrapping methods. Both methods provide 
Table 5

Coefficients for the CQR for selected percentiles.

\begin{tabular}{lccc}
\hline & tau $=\mathbf{0 . 2}$ & tau $=\mathbf{0 . 4}$ & tau $=\mathbf{0 . 6}$ \\
\hline (Intercept) & 0.03075102 & 0.1719855 & 0.4484115 \\
Private & 0.79813256 & 0.6873951 & 0.3808188 \\
Seashore & 0.17111642 & 0.1406194 & 0.1707697 \\
Large metropolitan area & 0.16678104 & 0.1961644 & 0.1014932 \\
Hub & 0.26062603 & 0.4912307 & 0.1015598 \\
International flights & -0.19745866 & -0.2898989 & -0.4401834 \\
\hline
\end{tabular}
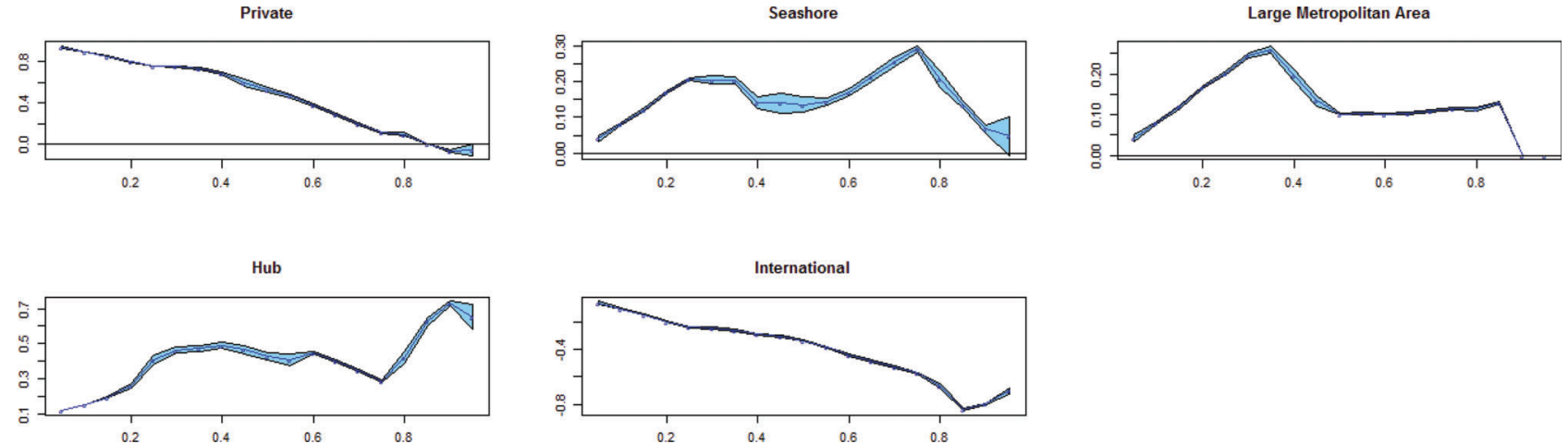

Figure 5. CQR coefficients plots. The solid blue line indicates the quantile regression point estimates; the lighter blue region is a pointwise 95\% confidence band. $X$-axis represents the quantiles and $Y$-axis represents the coefficients for each contextual variable.

robust results (Koenker \& Hallock, 2001), although the bootstrap method is preferred for being more practical (Hao \& Naiman, 2007). Therefore, the bootstrap results derived originally for the DEA scores were also used to bootstrap for the CQR coefficient estimates. As one can easily note from Table 5 , the signs of the relationships between the contextual variables and the efficiency levels are confirmed for different quantiles-when compared to results presented in Figure 4-although their magnitude may vary from quantile to quantile. As a matter of fact, this effect takes place because rather than predicting the mean of the dependent variable, CQR looks at the quantiles of the dependent variable. By choosing tau $=0.4$ or 0.6 , the 40 th and 60th percentiles of the data are being used to compute the regression. Therefore, $\mathrm{CQR}$ can answer the question: "For which type of Nigerian airport-high or low efficiency — does the impact of a given contextual variable prevail?"

The CQR results presented in Table 5 indicate that the effects of private ownership and location in a large metropolitan area have a larger positive impact on the lower quantiles of efficiency in Nigerian airports. For example, the 20th quantile of efficiency for private airports is roughly 0.798 percent points higher than for public airports in the same quantile. The airport that is privately owned or operated privately is OSUBI airport. This airport is owned by Shell Petroleum Company Limited. Moreso, Murtala Muhammed Airport Terminal II Lagos (MMA 2) is a concessional airport, operating under concession agreement. Conversely, the effects of international flights (negative) and hub operations (positive) are larger in higher quantiles of airport efficiency than in lower ones. Seashore location presents a somewhat more stable pattern for different quantiles, which can be inferred from Figure 5.

It is important to notice that in Figure $5 \mathrm{CQR}$ coefficients for the contextual variables cross the horizontal "effect equals zero" axis in some quantiles. Such crossovers are, however, sometimes quite plausible, and an advantage of the CQR approach is that they are more easily revealed (Koenker \& Geling, 2001). In this research, crossover occurs for efficiency quantiles higher than 0.90 for private airports, suggesting that airport privatization may be innocuous for high efficiency units and that their efficiency levels may even decrease, possibly due to congestion or insufficient resources to keep up with higher service level standards.

The results presented here suggest a number of policy implications for Nigerian airports, indicating different courses of action for airports with higher and lower efficiency levels. Lower efficiency airports clearly benefit more from private operations and are less impacted by international flights than higher efficiency airports, which are mostly benefited by hub operations and more penalized by international flights. While the focus of less efficient airports should be placed on ownership and location aspects-at the very beginning of the airport lifecyclethe more efficient airports should emphasize network connectivity issues, such as hub operations in order to act as a demand driver and also to counterbalance the negative effects of international flights. Authorities in Nigeria should consider the development of domestic hub operations in 
high-efficiency airports in parallel with alternative funding sources, so that capacity strangling and service deterioration can be avoided.

\section{Conclusions}

This article presented a novel two-stage approach based on bootstrapped DEA and CQR to assess the efficiency of Nigerian airports in the light of different contextual variables related to network connectivity, ownership, and location. Results indicated that higher and lower efficiency airports require different courses of action in order to maintain high service standards. Although the quantile results obtained for the less efficient airports are quite intuitive and corroborate previous literature-positive impact of private ownership and negative impact of international flights - the paths for maintaining high efficiency levels in more efficient airports are not trivial. Future research should address a deeper focus on higher efficiency airports in Nigeria, studying the role of capacity shortfalls and resource congestion as critical elements for such segments in keeping high standards of service.

\section{Appendix: Complete Results for the Censored Quantile Regression}

tau: [1] 0.05

Coefficients:

\begin{tabular}{lcccccc}
\hline & Value & Lower bound & Upper bound & Std error & $\boldsymbol{T}$ value & $\operatorname{Pr}(>|\boldsymbol{t}|)$ \\
\hline (Intercept) & 0.01785 & 0.01747 & 0.01824 & 0.00020 & 90.91761 & 0.00000 \\
Private & 0.93934 & 0.93055 & 0.94814 & 0.00449 & 209.37551 & 0.00000 \\
Seashore & 0.04107 & 0.03194 & 0.05020 & 0.00466 & 8.81709 & 0.00000 \\
Large metropolitan area & 0.04115 & 0.03202 & 0.05028 & 0.00466 & 8.83487 & 0.00000 \\
Hub & 0.12212 & 0.12147 & 0.12276 & 0.00033 & 371.26850 & 0.00000 \\
International flights & -0.05893 & -0.06807 & -0.04979 & 0.00466 & -12.63497 & 0.00000 \\
\hline
\end{tabular}

tau: [1] 0.1

Coefficients:

\begin{tabular}{lcccccc}
\hline & Value & Lower bound & Upper bound & Std error & $\boldsymbol{T}$ value & $\operatorname{Pr}(>|\boldsymbol{t}|)$ \\
\hline (Intercept) & 0.02311 & 0.02245 & 0.02378 & 0.00034 & 68.21447 & 0.00000 \\
Private & 0.89581 & 0.89346 & 0.89816 & 0.00120 & 747.05755 & 0.00000 \\
Seashore & 0.08108 & 0.07834 & 0.08381 & 0.00140 & 58.08884 & 0.00000 \\
Large metropolitan area & 0.08024 & 0.07765 & 0.08282 & 0.00132 & 60.77508 & 0.00000 \\
Hub & 0.15522 & 0.15469 & 0.15574 & 0.00027 & 579.33268 & 0.00000 \\
International flights & -0.10327 & -0.10552 & -0.10103 & 0.00114 & -90.23727 & 0.00000 \\
\hline
\end{tabular}

tau: [1] 0.15

Coefficients:

\begin{tabular}{lcccccc}
\hline & Value & Lower bound & Upper bound & Std error & $\boldsymbol{T}$ value & $\operatorname{Pr}(>|\boldsymbol{t}|)$ \\
\hline (Intercept) & 0.02685 & 0.02609 & 0.02761 & 0.00039 & 69.19329 & 0.00000 \\
Private & 0.85166 & 0.84699 & 0.85633 & 0.00238 & 357.32600 & 0.00000 \\
Seashore & 0.12149 & 0.11677 & 0.12621 & 0.00241 & 50.45206 & 0.00000 \\
Large metropolitan area & 0.11971 & 0.11507 & 0.12436 & 0.00237 & 50.50696 & 0.00000 \\
Hub & 0.19548 & 0.19143 & 0.19954 & 0.00207 & 94.51384 & 0.00000 \\
International flights & -0.14649 & -0.15110 & -0.14188 & 0.00235 & -62.30951 & 0.00000 \\
\hline
\end{tabular}


tau: [1] 0.2

Coefficients:

\begin{tabular}{lccccc}
\hline & Value & Lower bound & Upper bound & Std error & Pr $(>|\boldsymbol{t}|)$ \\
\hline (Intercept) & 0.03075 & 0.03042 & 0.03108 & 0.00017 & 182.69791 \\
Private & 0.79813 & 0.79483 & 0.80143 & 0.00168 & 474.32702 \\
Seashore & 0.17112 & 0.16809 & 0.17414 & 0.00154 & 0.00000 \\
Large metropolitan area & 0.16678 & 0.16344 & 0.17012 & 0.00171 & 0.00000 \\
Hub & 0.26063 & 0.24557 & 0.27568 & 0.00768 & 33.92804 \\
International flights & -0.19746 & -0.20094 & -0.19398 & 0.00177 & -111.32744 \\
\hline
\end{tabular}

tau: [1] 0.25

Coefficients:

\begin{tabular}{lcccccc}
\hline & Value & Lower bound & Upper bound & Std error & $\boldsymbol{T}$ value & $\operatorname{Pr}(>|t|)$ \\
\hline (Intercept) & 0.03724 & 0.03669 & 0.03779 & 0.00028 & 133.43641 & 0.00000 \\
Private & 0.75600 & 0.75249 & 0.75950 & 0.00179 & 422.72875 & 0.00000 \\
Seashore & 0.20676 & 0.20233 & 0.21119 & 0.00226 & 91.43608 & 0.00000 \\
Large metropolitan area & 0.20201 & 0.19798 & 0.20604 & 0.00206 & 98.25668 & 0.00000 \\
Hub & 0.40823 & 0.37981 & 0.43665 & 0.01450 & 28.15126 & 0.00000 \\
International flights & -0.23911 & -0.24241 & -0.23581 & 0.00169 & -141.90311 & 0.00000 \\
\hline
\end{tabular}

tau: [1] 0.3

Coefficients:

\begin{tabular}{lcccccc}
\hline & Value & Lower bound & Upper bound & Std error & $\boldsymbol{T}$ value & Pr $(>|t|)$ \\
\hline (Intercept) & 0.04480 & 0.04345 & 0.04615 & 0.00069 & 65.05123 & 0.00000 \\
Private & 0.75116 & 0.74175 & 0.76056 & 0.00480 & 156.57666 & 0.00000 \\
Seashore & 0.20404 & 0.19295 & 0.21513 & 0.00566 & 36.04863 & 0.00000 \\
Large metropolitan area & 0.24500 & 0.23853 & 0.25148 & 0.00330 & 74.17171 & 0.00000 \\
Hub & 0.46549 & 0.44727 & 0.48371 & 0.00930 & 50.07417 & 0.00000 \\
International flights & -0.24220 & -0.25105 & -0.23334 & 0.00452 & -53.61283 & 0.00000 \\
\hline
\end{tabular}

tau: [1] 0.35

Coefficients:

\begin{tabular}{lcccccc}
\hline & Value & Lower bound & Upper bound & Std error & $\boldsymbol{T}$ value & $\operatorname{Pr}(>|\boldsymbol{t}|)$ \\
\hline (Intercept) & 0.06313 & 0.05824 & 0.06802 & 0.00249 & 25.30687 & 0.00000 \\
Private & 0.73366 & 0.72640 & 0.74092 & 0.00370 & 198.07967 & 0.00000 \\
Seashore & 0.20321 & 0.19298 & 0.21344 & 0.00522 & 38.91717 & 0.00000 \\
Large metropolitan area & 0.25990 & 0.25191 & 0.26789 & 0.00408 & 63.74653 & 0.00000 \\
Hub & 0.47376 & 0.45881 & 0.48871 & 0.00763 & 62.10638 & 0.00000 \\
International flights & -0.25807 & -0.26568 & -0.25046 & 0.00388 & -66.44509 & 0.00000 \\
\hline
\end{tabular}


tau: [1] 0.4

Coefficients:

\begin{tabular}{lcccccc}
\hline & Value & Lower bound & Upper bound & Std error & $\boldsymbol{T}$ value & $\operatorname{Pr}(>|\boldsymbol{t}|)$ \\
\hline (Intercept) & 0.17199 & 0.16086 & 0.18311 & 0.00567 & 30.30713 & 0.00000 \\
Private & 0.68740 & 0.68060 & 0.69419 & 0.00347 & 198.17250 & 0.00000 \\
Seashore & 0.14062 & 0.12455 & 0.15668 & 0.00820 & 17.15597 & 0.00000 \\
Large metropolitan area & 0.19616 & 0.18125 & 0.21108 & 0.00761 & 25.77759 & 0.00000 \\
Hub & 0.49123 & 0.47306 & 0.50940 & 0.00927 & 52.99058 & 0.00000 \\
International flights & -0.28990 & -0.29444 & -0.28535 & 0.00232 & -124.99059 & 0.00000 \\
\hline
\end{tabular}

tau: [1] 0.45

Coefficients:

\begin{tabular}{lcccccc}
\hline & Value & Lower bound & Upper bound & Std error & $\boldsymbol{T}$ value & $\operatorname{Pr}(>|\boldsymbol{t}|)$ \\
\hline (Intercept) & 0.25972 & 0.24858 & 0.27087 & 0.00569 & 45.68252 & 0.00000 \\
Private & 0.60006 & 0.56758 & 0.63254 & 0.01657 & 36.20659 & 0.00000 \\
Seashore & 0.14022 & 0.11236 & 0.16808 & 0.01421 & 9.86485 & 0.00000 \\
Large metropolitan area & 0.13446 & 0.12153 & 0.14739 & 0.00660 & 20.38322 & 0.00000 \\
Hub & 0.46560 & 0.43921 & 0.49199 & 0.01346 & 34.57956 & 0.00000 \\
International flights & -0.30369 & -0.31133 & -0.29606 & 0.00390 & -77.96064 & 0.00000 \\
\hline
\end{tabular}

tau: [1] 0.5

Coefficients:

\begin{tabular}{lcccccc}
\hline & Value & Lower bound & Upper bound & Std error & $\boldsymbol{T}$ value & $\operatorname{Pr}(>|\boldsymbol{t}|)$ \\
\hline (Intercept) & 0.33651 & 0.33092 & 0.34211 & 0.00286 & 117.86028 & 0.00000 \\
Private & 0.52848 & 0.50960 & 0.54736 & 0.00963 & 54.85475 & 0.00000 \\
Seashore & 0.13500 & 0.11342 & 0.15658 & 0.01101 & 12.26117 & 0.00000 \\
Large metropolitan area & 0.10042 & 0.09917 & 0.10167 & 0.00064 & 157.45906 & 0.00000 \\
Hub & 0.42806 & 0.40874 & 0.44739 & 0.00986 & 43.41841 & 0.00000 \\
International flights & -0.33647 & -0.34205 & -0.33088 & 0.00285 & -117.98263 & 0.00000 \\
\hline
\end{tabular}

tau: [1] 0.55

Coefficients:

\begin{tabular}{lcccccc}
\hline & Value & Lower bound & Upper bound & Std error & $\boldsymbol{T}$ value & $\operatorname{Pr}(>|\boldsymbol{t}|)$ \\
\hline (Intercept) & 0.38916 & 0.38092 & 0.39741 & 0.00420 & 92.55340 & 0.00000 \\
Private & 0.46685 & 0.45243 & 0.48128 & 0.00736 & 63.43781 & 0.00000 \\
Seashore & 0.14398 & 0.13477 & 0.15320 & 0.00470 & 30.62457 & 0.00000 \\
Large metropolitan area & 0.10271 & 0.09992 & 0.10550 & 0.00142 & 72.24833 & 0.00000 \\
Hub & 0.40685 & 0.37351 & 0.44019 & 0.01701 & 23.91972 & 0.00000 \\
International flights & -0.38464 & -0.39133 & -0.37796 & 0.00341 & -112.77803 & 0.00000 \\
\hline
\end{tabular}


tau: [1] 0.6

Coefficients:

\begin{tabular}{|c|c|c|c|c|c|c|}
\hline & Value & Lower bound & Upper bound & Std error & $T$ value & $\operatorname{Pr}(>|t|)$ \\
\hline (Intercept) & 0.44841 & 0.44065 & 0.45617 & 0.00396 & 113.20799 & 0.00000 \\
\hline Private & 0.38082 & 0.36638 & 0.39526 & 0.00737 & 51.67624 & 0.00000 \\
\hline Seashore & 0.17077 & 0.16096 & 0.18058 & 0.00500 & 34.13410 & 0.00000 \\
\hline Large metropolitan area & 0.10149 & 0.09887 & 0.10412 & 0.00134 & 75.85169 & 0.00000 \\
\hline Hub & 0.45010 & 0.44204 & 0.45815 & 0.00411 & 109.49506 & 0.00000 \\
\hline International flights & 0.44018 & -0.44791 & -0.43245 & 0.00394 & -111.61841 & 0.00000 \\
\hline
\end{tabular}

tau: [1] 0.65

Coefficients:

\begin{tabular}{lccccc}
\hline & Value & Lower bound & Upper bound & Std error & Pr $(>|\boldsymbol{t}|)$ \\
\hline (Intercept) & 0.49583 & 0.48718 & 0.50448 & 0.00441 & 112.34631 \\
Private & 0.29172 & 0.28185 & 0.30160 & 0.00504 & 57.87830 \\
Seashore & 0.21245 & 0.20133 & 0.22357 & 0.00568 & 37.43268 \\
Large metropolitan area & 0.10226 & 0.10005 & 0.10446 & 0.00112 & 0.00000 \\
Hub & 0.40191 & 0.39508 & 0.40875 & 0.00349 & 115.30411 \\
International flights & -0.48318 & -0.49200 & -0.47436 & 0.00450 & -107.35976 \\
\hline
\end{tabular}

tau: [1] 0.7

Coefficients:

\begin{tabular}{|c|c|c|c|c|c|c|}
\hline & Value & Lower bound & Upper bound & Std error & $T$ value & $\operatorname{Pr}(>|t|)$ \\
\hline (Intercept) & 0.54263 & 0.53465 & 0.55060 & 0.00407 & 133.28972 & 0.00000 \\
\hline Private & 0.20130 & 0.19250 & 0.21011 & 0.00449 & 44.80546 & 0.00000 \\
\hline Seashore & 0.25607 & 0.24201 & 0.27014 & 0.00717 & 35.68992 & 0.00000 \\
\hline Large metropolitan area & 0.10836 & 0.10549 & 0.11123 & 0.00146 & 73.99687 & 0.00000 \\
\hline Hub & 0.34901 & 0.34230 & 0.35573 & 0.00343 & 101.89296 & 0.00000 \\
\hline International flights & -0.52751 & -0.53528 & -0.51974 & 0.00396 & -133.10153 & 0.00000 \\
\hline
\end{tabular}

tau: [1] 0.75

Coefficients:

\begin{tabular}{lcccccc}
\hline & Value & Lower bound & Upper bound & Std error & $\boldsymbol{T}$ value & Pr $(>|t|)$ \\
\hline (Intercept) & 0.59449 & 0.58709 & 0.60189 & 0.00377 & 157.49089 & 0.00000 \\
Private & 0.11519 & 0.11256 & 0.11781 & 0.00134 & 85.85837 & 0.00000 \\
Seashore & 0.29033 & 0.28266 & 0.29799 & 0.00391 & 74.19556 & 0.00000 \\
Large metropolitan area & 0.11519 & 0.11256 & 0.11781 & 0.00134 & 85.85837 & 0.00000 \\
Hub & 0.29033 & 0.28266 & 0.29799 & 0.00391 & 74.19556 & 0.00000 \\
International flights & -0.57426 & -0.58162 & -0.56689 & 0.00376 & -152.85036 & 0.00000 \\
\hline
\end{tabular}


tau: [1] 0.8

Coefficients:

\begin{tabular}{lcccccc}
\hline & Value & Lower bound & Upper bound & Std error & $\boldsymbol{T}$ value & $\operatorname{Pr}(>|\boldsymbol{t}|)$ \\
\hline (Intercept) & 0.69259 & 0.67511 & 0.71007 & 0.00892 & 77.66045 & 0.00000 \\
Private & 0.10156 & 0.08436 & 0.11876 & 0.00877 & 11.57560 & 0.00000 \\
Seashore & 0.20585 & 0.18366 & 0.22804 & 0.01132 & 18.17925 & 0.00000 \\
Large metropolitan area & 0.11317 & 0.10920 & 0.11713 & 0.00202 & 55.94815 & 0.00000 \\
Hub & 0.42235 & 0.39017 & 0.45452 & 0.01642 & 25.72814 & 0.00000 \\
International flights & -0.66466 & -0.68217 & -0.64715 & 0.00894 & -74.38315 & 0.00000 \\
\hline
\end{tabular}

tau: [1] 0.85

Coefficients:

\begin{tabular}{lcccccc}
\hline & Value & Lower bound & Upper bound & Std error & $\boldsymbol{T}$ value & $\operatorname{Pr}(>|t|)$ \\
\hline (Intercept) & 0.86697 & 0.85666 & 0.87728 & 0.00526 & 164.79399 & 0.00000 \\
Private & 0.00000 & 0.00000 & 0.00000 & 0.00000 & NaN & NaN \\
Seashore & 0.13303 & 0.12272 & 0.14334 & 0.00526 & 25.28602 & 0.00000 \\
Large metropolitan area & 0.12958 & 0.12598 & 0.13317 & 0.00183 & 70.70863 & 0.00000 \\
Hub & 0.62717 & 0.60312 & 0.65122 & 0.01227 & 51.11062 & 0.00000 \\
International flights & -0.83549 & -0.84534 & -0.82565 & 0.00502 & -166.30952 & 0.00000 \\
\hline
\end{tabular}

tau: [1] 0.9

Coefficients:

\begin{tabular}{lcccccc}
\hline & Value & Lower bound & Upper bound & Std error & $\boldsymbol{T}$ value & $\operatorname{Pr}(>|\boldsymbol{t}|)$ \\
\hline (Intercept) & 1.00000 & 1.00000 & 1.00000 & 0.00000 & Inf & 0.00000 \\
Private & -0.06730 & -0.07916 & -0.05545 & 0.00605 & -11.12698 & 0.00000 \\
Seashore & 0.06730 & 0.05545 & 0.07916 & 0.00605 & 11.12698 & 0.00000 \\
Large metropolitan area & 0.00000 & 0.00000 & 0.00000 & 0.00000 & $\mathrm{NaN}$ & NaN \\
Hub & 0.72974 & 0.71913 & 0.74036 & 0.00542 & 134.73316 & 0.00000 \\
International flights & -0.79705 & -0.80270 & -0.79140 & 0.00288 & -276.42408 & 0.00000 \\
\hline
\end{tabular}

tau: [1] 0.95

Coefficients:

\begin{tabular}{lcccccc}
\hline & Value & Lower bound & Upper bound & Std error & $\boldsymbol{T}$ value & $\operatorname{Pr}(>|\boldsymbol{t}|)$ \\
\hline (Intercept) & 1.00000 & 1.00000 & 1.00000 & 0.00000 & $\mathrm{Inf}$ & 0.00000 \\
Private & -0.04860 & -0.10277 & 0.00557 & 0.02764 & -1.75858 & 0.07865 \\
Seashore & 0.04860 & -0.00557 & 0.10277 & 0.02764 & 1.75858 & 0.07865 \\
Large metropolitan area & 0.00000 & 0.00000 & 0.00000 & 0.00000 & $\mathrm{NaN}$ & $\mathrm{NaN}$ \\
Hub & 0.65302 & 0.58195 & 0.72410 & 0.03626 & 18.00784 & 0.00000 \\
International flights & -0.70162 & -0.72404 & -0.67921 & 0.01144 & -61.35086 & 0.00000 \\
\hline
\end{tabular}




\section{References}

Adler, N., \& Berechman, J. (2001). Measuring airport quality from the airlines' viewpoint: An application of data envelopment analysis. Transport Policy, 8, 171-181. https://doi.org/10.1016/S0967-070X (01)00011-7

Alvarez, A. Arias, C., \& Greene, W. (2004). Accounting for unobservables in production models: Management and inefficiency. Econometric Society, $1-20$

Assaf, A. (2010). Bootstrapped scale efficiency measures of UK airports. Journal of Air Transport Management, 16, 42-44. https://doi.org/ 10.1016/j.jairtraman.2009.03.001

Banker, R. D., Charnes, A., \& Cooper, W. W. (1984). Some models for the estimation of technical and scale inefficiencies in Data Envelopment Analysis. Management Science, 30, 1078-1092.

Barbot, C., Costa, Á., \& Sochirca, E. (2008). Airlines performance in the new market context: A comparative productivity and efficiency analysis. Journal of Air Transport Management, 14, 270-274. https://doi.org/ 10.1016/j.jairtraman.2008.05.003

Barros, C. P. (2009). The measurement of efficiency of UK airports, using a stochastic latent class frontier model. Transport Reviews, 29, 479-498. https://doi.org/10.1080/01441640802525418

Barros, C. P. (2014). Airports and tourism in Mozambique. Tourism Management, 41, 76-82. https://doi.org/10.1016/j.tourman.2013.08.007

Barros, C. P., \& Dieke, P. U. C. (2007). Performance evaluation of Italian airports: A data envelopment analysis. Journal of Air Transport Management, 13, 184-191. https://doi.org/10.1016/j.jairtraman.2007.03.001

Barros, C. P., \& Dieke, P. U. C. (2008). Measuring the economic efficiency of airports: A Simar-Wilson methodology analysis. Transportation Research Part E: Logistics and Transportation Review, 44, 1039-1051. https://doi.org/10.1016/j.tre.2008.01.001

Barros, C. P., Wanke, P., Nwaogbe Obioma, R., \& Azad, M. A. K. (2017). Efficiency in Nigerian airports. Case Studies on Transport Policy, 5, 573-579. https://doi.org/10.1016/j.cstp.2017.10.003

Bazargan, M., \& Vasigh, B. (2003). Size versus efficiency: A case study of US commercial airports. Journal of Air Transport Management, 9, 187-193. https://doi.org/10.1016/S0969-6997(02)00084-4

Bezerra, G. C. L., \& Gomes, C. F. (2016). Performance measurement in airport settings: A systematic literature review. Benchmarking: An International Journal, 23, 1027-1050. https://doi.org/10.1108/BIJ10-2015-0099

Bogetoft, P., \& Otto, L. (2010). Benchmarking with DEA, SFA, and R. New York, NY: Springer Science \& Business Media.

Bråthen, S. (2016). Air transport provision in remoter regions. New York, NY: Routledge.

Cesaro, L., Marongiu, S., Arfini, F., Donati, M., \& Capelli, M. G. (2009). Methodology for analysing competitiveness, efficiency and economy of scale-Use and applications of DEA. FACEPA Deliverable D5.13 (April). Retrieved from http://www.ekon.slu.se/facepa

Charnes, A., Cooper, W. W., \& Rhodes, E. (1978). Measuring the efficiency of decision making units. European Journal of Operational Research, 2(6), 429-444.

Cooper, W. W., Park, K. S., \& Yu, G. (2001). An illustrative application of IDEA to a Korean mobile telecommunication company. Operations Research, 49, 807-820. https://doi.org/10.1287/opre,49,6.807.10022

Diana, T. (2010). Can we explain airport performance? A case study of selected New York airports using a stochastic frontier model. Journal of Air Transport Management, 16, 310-314. https://doi.org/10.1016/ j.jairtraman.2010.03.006

Gillen, D., \& Lall, A. (1997). Developing measures of airport productivity and performance: An application of data envelopment analysis. Transportation Research Part E: Logistics and Transportation Review, 33, 261-273. https://doi.org/10.1016/S1366-5545(97)00028-8

Gitto, S., \& Mancuso, P. (2012). Bootstrapping the Malmquist indexes for Italian airports. International Journal of Production Economics, 135, 403-411. https://doi.org/10.1016/j.ijpe.2011.08.014
Hao, L., \& Naiman, D. Q. (2007). Quantile Regression. Thousand Oaks, CA: Sage.

Hong, H., \& Chernozhukov, V. (2002). Three-step censored quantile regression and extramarital affairs. Journal of the American Statistical Association, 97, 872-882.

Jin, Z., Ying, Z., \& Wei, L. J. (2001). A simple resampling method by perturbing the minimand. Biometrika, 88, 381-390. MR1844838

Kalbfleisch, J. D., \& Prentice, R. L. (2002). The Statistical Analysis of Failure Time Data (2nd Ed.). New York: Wiley.

Koenker, R., and Bassett, G. S. (1978). Regression quantiles. Econometrica, 46, 33-50.

Koenker, R., \& Geling, O. (2001). Reappraising Medfly longevity. Journal of the American Statistical Association, 96, 458-468. https:// doi.org/10.1198/016214501753168172

Koenker, R., \& Hallock, K. F. (2001). Quantile regression. Journal of Economic Perspectives, 15(4),143-156.

Koenker, R., \& d'Orey, V. (1987). Computing regression quantiles. Applied Statistics, 36, 383-393.

Lai, P. L., Potter, A., Beynon, M., \& Beresford, A. (2015). Evaluating the efficiency performance of airports using an integrated AHP/DEA-AR technique. Transport Policy, 42, 75-85. https://doi.org/10.1016/j.tranpol. 2015.04.008

Leng, \& Tong, X. (2013) A quantile regression estimator for censored data, Bernoulli 19 (1), 344-361. https://doi.org/10.3150/11-BEJ388

Liu, J. S., Lu, L. Y. Y., Lu, W.-M., \& Lin, B. J. Y. (2013). A survey of DEA applications. Omega-International Journal of Management Science, 41, 893-902. https://doi.org/10.1016/j.omega.2012.11.004

Lozano, S., \& Gutiérrez, E. (2011). Efficiency analysis and target setting of Spanish airports. Networks and Spatial Economics, 11, 139-157. https://doi.org/10.1007/s11067-008-9096-1

Marques, R. C., \& Simões, P. (2010). Measuring the influence of congestion on efficiency in worldwide airports. Journal of Air Transport Management, 16, 334-336. https://doi.org/10.1016/j.jairtraman.2010.03.002

Martin, J. C., \& Roman, C. (2001). An application of DEA to measure the efficiency of Spansih airports prior to privatisation. Journal of Air Transport Management, 7, 149-157.

Odeck, J., \& Alkadi, A. (2001). The performance of subsidized urban and rural public bus operators: Empirical evidence from Norway. The Annals of Regional Science, 38(3), 413-431.

Powell, J. L. (1984). Least absolute deviations estimation for the censored regression model. Journal of Econometrics, 25, 303-325. MR0752444

Powell, J. L. (1986). Censored regression quantiles. Journal of Econometrics, 32, 143-155. MR0853049

Ray, S. C. (2010). A one-step procedure for return to scale classification of decision making units in data envelopment analysis, working paper 2010-07. Retrieved from http://www.econ.unconn.edu/

Sarkis, J. (2000). An analysis of the operational efficiency of major airports in the United States. Journal of Operations Management, 18, 335-351. https://doi.org/10.1016/S0272-6963(99)00032-7

Schefczyk, M. (1993). Operational performance of airlines: An extension of traditional measurement paradigms. Strategic Management Journal, 14, 301-317. https://doi.org/10.1002/smj.4250140406

Simar, L., \& Wilson, P. W. (1998). Sensitivity analysis of efficiency scores: How to bootstrap in Nonparametric Frontier Models, Management Science, 44, 49-61.

Simar, L., \& Wilson, P. W. (2000). A general methodology for bootstrapping in nonparametric frontier models. Journal of Applied Statistics, 27(6), 779-802.

Simar, L., Wilson, P. W. (2004). Performance of the bootstrap for DEA estimators and iterating the principle. In, W. W. Cooper, L. M. Seiford, J. Zhu (Eds.), Handbook on Data Envelopment Analysis. Boston: Kluwer Academic Publishers, 265-298.

Tavassoli, M., Faramarzi, G. R., \& Farzipoor Saen, R. (2014). Efficiency and effectiveness in airline performance using a SBM-NDEA model in the presence of shared input. Journal of Air Transport Management, 34, 146-153. https://doi.org/10.1016/j.jairtraman.2013.09.001 
Titko, J., Stankevičienè, J., \& Lāce, N. (2014). Measuring bank efficiency: DEA application. Technological and Economic Development of Economy, 20, 739-757. https://doi.org/10.3846/20294913.2014.984255

Tsekeris, T. (2011). Greek airports: Efficiency measurement and analysis of determinants. Journal of Air Transport Management, 17(3), $140-142$.

Tsui, W. H. K., Balli, H. O., Gilbey, A., \& Gow, H. (2014a). Operational efficiency of Asia-Pacific airports. Journal of Air Transport Management, 40, 16-24. https://doi.org/10.1016/j.jairtraman.2014. 05.003

Tsui, W. H. K., Gilbey, A., \& Balli, H. O. (2014b). Estimating airport efficiency of New Zealand airports. Journal of Air Transport Management, 35, 78-86. https://doi.org/10.1016/j.jairtraman.2013.11.011

Wanke, P. (2013). Physical infrastructure and flight consolidation efficiency drivers in Brazilian airports: A two-stage network-DEA approach Journal of Air Transport Management, 31, 1-5. https://doi.org/ 10.1016/j.jairtraman.2012.09.001

Wanke, P., \& Barros, C. P. (2016). Efficiency in Latin American airlines: A two-stage approach combining virtual frontier dynamic DEA and simplex regression. Journal of Air Transport Management, 54, 93-103. https://doi.org/10.1016/j.jairtraman.2016.04.001

Wanke, P., Barros, C. P., \& Nwaogbe Obioma, R. (2016). Assessing productive efficiency in Nigerian airports using Fuzzy-DEA. Transport Policy, 49, 9-19. https://doi.org/10.1016/j.tranpol.2016.03.012
Ying, Z., Jung, S. H., \& Wei, L. J. (1995). Survival analysis with median regression models. Journal of American Statistics Association, 90, 178-184. MR1325125

Yoshida, Y., \& Fujimoto, H. (2004). Japanese-airport benchmarking with the DEA and endogenous-weight TFP methods: Testing the criticism of overinvestment in Japanese regional airports. Transportation Research Part E: Logistics and Transportation Review, 40, 533-546. https://doi.org/ 10.1016/j.tre.2004.08.003

Yu, M.-M. (2010). Assessment of airport performance using the SBM-NDEA model. Omega, 38, 440-452. https://doi.org/10.1016/j.omega.2009.11.003

Zhu J. (2003). Quantitative models for performance evaluation and benchmarking Data Envelopment Analysis with spreadsheets and DEA Excel Solver. New York, NY: Kluwer Academic Publishers.

Obioma Reuben Nwaogbe has a BTech, MSc, and $\mathrm{PhD}$ (in view) in transport management.

Peter Wanke has a BSc, MSc, and PhD in economics.

Innocent C. Ogwude has a BSc, MEng, and $\mathrm{PhD}$ in transport economics.

Carlos Pestana Barroso has a BSc, MSc, and PhD in economics.

Abul Kalam Azad has a BSc, MSc, and PhD in statistics. 